On the Origin of Diamond Plates Deposited at Low Temperature

Peer-reviewed author version

DRIJKONINGEN, Sien; POBEDINSKAS, Paulius; Korneychuk, Svetlana; MOMOT, Aleksandr; BALASUBRAMANIAM, Yaso; VAN BAEL, Marlies; TURNER, Stuart;

Verbeeck, Jo; NESLADEK, Milos \& HAENEN, Ken (2017) On the Origin of Diamond

Plates Deposited at Low Temperature. In: CRYSTAL GROWTH \& DESIGN, 17(8), p. 4306-4314.

DOI: 10.1021/acs.cgd.7b00623

Handle: http://hdl.handle.net/1942/24974 


\section{On the origin of diamond plates deposited at low temperature}

Sien Drijkoningen ${ }^{1,2, *}$, Paulius Pobedinskas ${ }^{1,2}$, Svetlana Korneychuk ${ }^{3}$, Aleksandr Momot ${ }^{1,2}$, Yasodhaadevi Balasubramaniam ${ }^{1,2}$, Marlies K. Van Bael ${ }^{1,2}$, Stuart Turner ${ }^{3}$, Jo Verbeeck ${ }^{3}$, Miloš Nesládek ${ }^{1,2}$, and Ken Haenen ${ }^{1,2,+}$

${ }^{1}$ Institute for Materials Research (IMO), Hasselt University, Wetenschapspark 1, B-3590 Diepenbeek, Belgium

2 IMOMEC, IMEC vzw, Wetenschapspark 1, B-3590 Diepenbeek, Belgium

3 Electron Microscopy for Materials Science (EMAT), University of Antwerp, Antwerp, Belgium

KEYWORDS low temperature diamond deposition, diamond plates, LA MW PE CVD

The crucial requirement for diamond growth at low temperatures, enabling a wide range of new applications, is a high plasma density at a low gas pressure, which leads to a low thermal load onto sensitive substrate materials. While these conditions are not within reach for resonance cavity plasma systems, linear antenna microwave delivery systems allow the deposition of high quality diamond films at temperatures around $400^{\circ} \mathrm{C}$ and at pressures below 1 mbar. In this work the co-deposition of high quality plates and octahedral diamond grains in nanocrystalline films is reported. In contrast to previous reports claiming the need of high temperatures $(T \geq$ $\left.850{ }^{\circ} \mathrm{C}\right)$, low temperatures $\left(320^{\circ} \mathrm{C} \leq \mathrm{T} \leq 410^{\circ} \mathrm{C}\right)$ were sufficient to deposit diamond plate structures. Cross-sectional high resolution transmission electron microscopy studies show that these plates are faulty cubic diamond terminated by large $\{111\}$ surface facets with very little $\mathrm{sp}^{2}$ bonded carbon in the grain boundaries. Raman and electron energy loss spectroscopy confirm a high diamond quality, above $93 \% \mathrm{sp}^{3}$ carbon content. Three potential mechanisms, that can account for the initial development of the observed plates rich with stacking faults, and are based on the presence of impurities, are proposed. 


\section{Introduction}

The growth of diamond thin films, especially at low temperatures, is attracting increasingly more interest due to its suitability for a wide variety of applications, such as biosensing, lubricity or corrosion protective layers. In addition, diamond nanostructures are being considered for nano-applications, i.e. diamond nanowires, plates or needles are promising materials for applications, such as field and thermionic emitters, ${ }^{1,2}$ nanophotonics ${ }^{3}$ and drug delivery systems ${ }^{4}$. Despite interesting properties, such as high hardness, good thermal conductivity, biocompatibility, chemical hardness and doping possibility, control over the morphology and crystal orientation remains challenging. Therefore direct deposition of the desired diamond morphology offers significant benefits over techniques that need to process the diamond grains into the desired shape after deposition. Moreover, as many of diamond's properties are influenced by the crystallographic orientation of its surface facets, insight into the growth of a particular morphology would be highly valuable. For chemical vapour deposition (CVD) of diamond the influence of the growth parameters on the resulting nanocrystalline film has been studied extensively already and a so-called alpha parameter, which is given by the relative growth rates on (100) and (111) facets, determines the most common crystal planes. ${ }^{5}$ A recent model by Silva et al. even introduced $\beta$ and $\gamma$ parameters, further clarifying the growth parameter window and the link between deposition conditions and the eventual film orientation. ${ }^{6}$ Nevertheless, actual control over these parameters is difficult, and the most encountered diamond morphology consists of octahedral grains, although efforts have been made for the direct fabrication of diamond nanostructures. ${ }^{7,8}$ An interesting morphology that has only been reported by a limited number of researchers is the diamond plate structure. First discovered by Angus et al. ${ }^{9}$ in 1992, it was later confirmed by Chang and colleagues, both using microwave plasma enhanced CVD (MW PE CVD). ${ }^{10,11}$ Very recently, 
Alexeev and co-workers also observed the plate morphology using direct current discharge PECVD. ${ }^{12}$ Although this morphology was previously referred to as diamond 'platelets' in these works, a more precise term is 'plates', avoiding confusion with the aggregated nitrogen defect in single crystal diamond, known as 'platelets' since $1977 .{ }^{13}$

According to Angus et al., the formation of hexagonally shaped plates, together with to octahedral grains, during the first stages of growth can be attributed to re-entrant grooves, i.e. corners of $141.1^{\circ}$, inward into the crystal, between neighbouring $\{111\}$ planes sharing a $\{111\}$ twin plane. These re-entrant grooves originate from stacking errors and they are preferred nucleation sites for $\{111\}$ faceted diamond crystals as reported by Angus et al. based on a model adopted from Hamilton and Seidensticker. ${ }^{9,14}$ A stacking fault can be considered as one or more adjacent layers of so-called hexagonal diamond, also known as lonsdaleite, or multiple layers of hexagonal diamond separated by correctly stacked cubic layers. The cause of these stacking faults remains unclear, but once formed they continue to exist due to their self-regenerating nature. To complete a new layer at a stacking fault location, only 2 atoms are required in every consecutive layer, while for cubic diamond three ad-atoms are needed for stable addition. This means that the creation of a stable nucleation site at a stacking fault has a higher probability than the consecutive addition of 3 atoms at regular $\{111\}$ crystal terminating surfaces. However, once one stable nucleation site is formed at a $\{111\}$ surface, the entire surface will grow by step-flow by means of atom attachment to the edge. Since the crystal grows normal to the [111] direction, the available surface area increases and the probability for the formation of a stable nucleation site increases as well. The layers of lonsdaleite form parallel to the $\{111\}$ diamond plane and eventually a hexagonal plate is formed due to the nature of a stacking error. Each error causes a $60^{\circ}$ rotation about an axis normal to the $\{111\}$ plane. ${ }^{9}$ 
High resolution transmission electron microscopy (TEM) results on diamond plate structures, published in 2004 by Chang and colleagues, however, reveal only a ridge side face structure, which makes it uncertain that the model proposed by Angus is the only one responsible for diamond plate growth, as there is no clear indication for re-entrant grooves. The sub-step model, originally proposed by Ming et al. and adopted by Chang and co-workers for diamond deposition, can also account for the emergence of plate diamond structures. ${ }^{11,15}$ In this model the existence of (multiparallel) twins is of key importance. The sub-step model is based on the assumption that $\{100\}$ faces grow faster than $\{111\}$, because there are more neighbours for adatoms which leads to a higher nucleation rate on $\{100\}$. The $\{100\}$ faces will grow until they reach the twin plane, i.e. ridge edge, where nucleation is preferred compared to flat $\{111\}$ faces because again only 2 ad-atoms are necessary for a stable nucleation site. Further growth proceeds along the $\{111\}$ face to complete the ridge edge, with the addition of only 2 atoms necessary in every step to form a stable nucleation site, which means this sub-step site is regenerative. Similar $\{100\} /\{111\}$ ridge-and-trough side faces are known to occur for noble metals or silver halides. ${ }^{16,17}$ After the adoption of the sub-step model to account for plate formation, the group of Chang and co-workers has done more work on the synthesis and characterization of diamond plate structures..$^{10,18-20}$ In all of their experiments, the deposition of diamond plates requires high temperature $\left(>1100{ }^{\circ} \mathrm{C}\right)$ and low methane concentration $(<3$ $\%$ ) and often a foreign material is present, such as $\mathrm{N}, \mathrm{Fe}, \mathrm{Au}-\mathrm{Ge}$. Both plates with $\{111\}$ and $\{110\}$ terminating or tabular faces have been synthesized.

The most recent report of diamond plates was by Alexeev and colleagues in the beginning of $2016 .{ }^{12}$ In their work the plates are composed of stacked $\{111\}$ diamond planes and TEM confirms the presence of planar stacking faults or twin boundaries in $\{111\}$. Multiple diamond plates intersect at about $70.5^{\circ}$, which corresponds to intersection angle between $\{111\}$ planes in cubic crystal structures and confirms the $\{111\}$ nature. To explain the emergence of plates, 
again high temperature and low methane concentration are believed to be of key importance, together with the re-entrant groove model.

Monte Carlo simulations done by Sunkara have shown that while one stacking fault on parallel \{111\} planes lead to slowly growing triangular plates, two or more stacking faults lead to hexagonal plates. ${ }^{21}$ Moreover, hexagonal plate development is in agreement with a kinetic and thermodynamic approach of modified Wulff constructions for twinned nanoparticles adopted by Ringe et al. ${ }^{22}$ According to their model, a hexagonal plate can be obtained with fast $\{100\}$ growth (compared to slow $\{111\}$ growth) and enhanced twin growth, which means that all faces adjacent to the twin plane grow equally fast.

A plausible mechanism for the occurrence of stacking faults on $\{111\}$ surfaces was described by Butler and Oleynik in $2008 .^{23}$ In order to create a stable nucleus on $\{111\}$ at least four carbon atoms need to be bonded to this $\{111\}$ surface and to each other. In the first step a three-atom bridge is formed between adjacent carbon atom sites on the $\{111\}$ surface by subsequent abstraction of atomic hydrogen and reversible carbon adsorbate additions. This three-atom bridge rapidly isomerises between the well-known boat and chair conformation, because they are similar in energy, until it is locked in either of the two positions by the addition of a fourth carbon. The nucleus formed has four bonds to the diamond surface and is thus very stable. Because of the similarity in energy, the created nucleus has almost $50 \%$ chance of being a stacking fault.

In this work, the co-deposition of high quality plate-like and octahedral diamond grains in nanocrystalline films with the use of a linear antenna MW PE CVD (LA MW PE CVD) system is reported. According to our current knowledge, this morphology has not been reported using LA MW PE CVD. ${ }^{24-26}$ In contrast to previous reports claiming the need of high temperatures $\left(\mathrm{T} \geq 850{ }^{\circ} \mathrm{C}\right),{ }^{9-12}$ low temperatures $\left(320^{\circ} \mathrm{C} \leq \mathrm{T} \leq 410{ }^{\circ} \mathrm{C}\right)$ were sufficient to deposit diamond plate structures. Although, Butler and Oleynik postulate that there is approximately $50 \%$ 
chance for twin formation during growth of diamond by CVD, other possible mechanisms for the formation of diamond plates will be proposed. Since the presence of impurity atoms is known to influence crystal growth in general, ${ }^{27,28}$ this papers aims to investigate the influence of impurity atoms on the crystal formation during diamond CVD deposition using LA MW PE CVD.

\section{Experimental Details}

Silicon (100) substrates (p-type, 10-20 k $\Omega \mathrm{cm}, 1 \times 1 \mathrm{~cm} 2$ ) were cleaned with standard RCA-1 and RCA-2 procedures. ${ }^{29}$ The substrates were seeded with a water-based colloidal suspension of ultradispersed detonation diamond via drop casting and subsequent spin-drying. ${ }^{30}$ The suspension of detonation nanodiamonds from NanoCarbon Institute Co., Ltd., features a zeta potential of $(45 \pm 5) \mathrm{mV}$ and contains particles with a size of 6-7 nm. The growth of $130 \mathrm{~nm}$ thick nanocrystalline diamond (NCD) layers was performed in an LA MW PE CVD system using a plasma containing $2.5 \%$ methane and $6 \%$ carbon dioxide in hydrogen. Carbon dioxide is added during growth because the presence of oxygen ensures effective etching of $\mathrm{sp}^{2}$ carbon phases at low temperatures, ${ }^{31,32}$ and this has shown to be beneficial for diamond growth in linear antenna systems. ${ }^{33}$ The film thickness was monitored by in-situ laser reflection interferometry. The microwave power and pressure were $2800 \mathrm{~W}$ and 0.18 Torr respectively.

The NCD layers were characterized with a FEI Quanta 200 FEG scanning electron microscope (SEM) operated at $15 \mathrm{kV}$ and with a Horiba Jobin Yvon T64000 Raman spectrometer equipped with a BXFM Olympus 9/128 microscope, a Horiba JY Symphony CCD detector and a $488 \mathrm{~nm}$ Lexell SHG laser. For plasma characterisation via optical emission spectroscopy, an optical fiber (Avantes FC UV600-2) collects the emitted light through one of the top windows and transfers it to an AvaSpec-2048 (Avantes) spectrometer which records the spectrum. 
Transmission Electron Microscopy (TEM) was performed with a FEI Titan cubed transmission electron microscope with a probe aberration corrector at $300 \mathrm{kV}$. Energy-dispersive X-ray spectroscopy (EDX) mapping was done using a Bruker Super-X detector and electron energy loss spectroscopy (EELS) was performed with a Gatan Enfinium electron spectrometer. Both the detector and the spectrometer are built-in into the Cubed Titan TEM and $300 \mathrm{kV}$ was used.

\section{Results and Discussion}

Shortly after the start of the growth (1h), some features with a high aspect ratio seem to have started to develop already as shown in figure 1a, i.e. the plates develop at the start of the growth, together with octahedral diamond particles. Figure $1 \mathrm{~b}$ shows the surface morphology of an NCD covered Si substrate grown in the LA system $\left(410{ }^{\circ} \mathrm{C}, 0.17 \mathrm{Torr}, 2.8 \mathrm{~kW} \mathrm{CW}\right.$ power, $2.5 \%$ $\mathrm{CH}_{4}$ and $6 \% \mathrm{CO}_{2}$, no external heating). The resulting 130 nanometre thick NCD layer is faceted and consists of both octahedral and plate-like diamond grains with a homogeneous distribution. The diamond plates are not parallel to the substrate but found in a variety of orientations. Both the plates and the octahedral particles are faceted, suggesting their crystalline nature. Each plate shows a uniform thickness and a high length-to-thickness aspect ratio, i.e. between 5 and 15 . If the growth is continued for $64 \mathrm{~h}$, the layer evolves into microcrystalline diamond (Fig. 1c-e). 

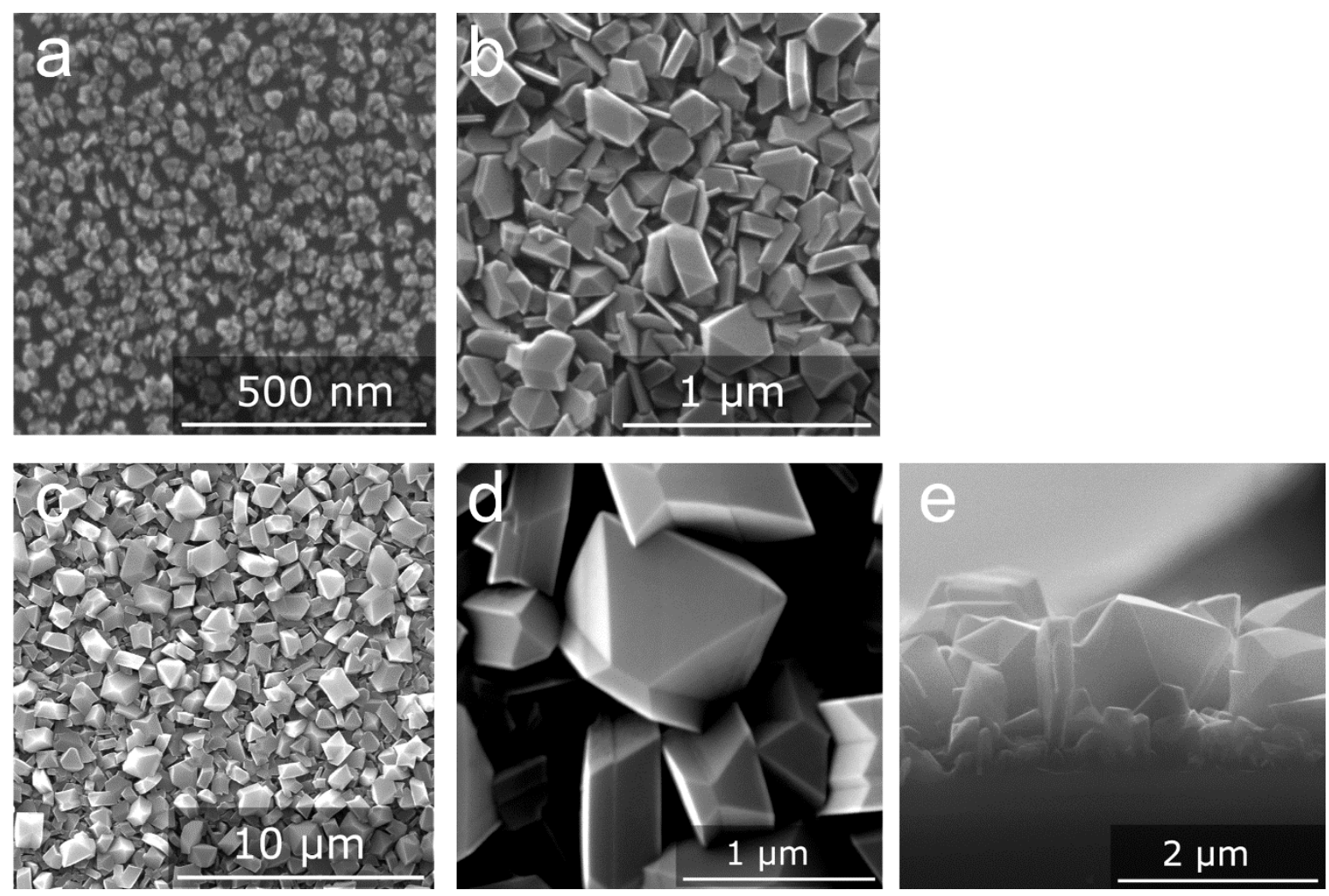

FIGURE 1. SEM images of samples grown at $410{ }^{\circ} \mathrm{C}, 0.17$ Torr, $2.8 \mathrm{~kW} \mathrm{CW}$ power, $2.5 \% \mathrm{CH}_{4}$ and $6 \% \mathrm{CO}_{2}$ without external heating. a) Initial stages (1h) of growth: the development of plate structures has started already. b) A $130 \mathrm{~nm}$ thick NCD layer (18h growth time) consists of both octahedral and plate-type diamond grains. c) A $1.5 \mu \mathrm{m}$ thick NCD layer (64h of growth) still consists of both octahedral and plate-type diamond grains. Prolonged growth times give rise to similar morphologies with larger grains. d) Zoom of (c), e) Cross-sectional view of (c) which demonstrates that the plate structures are present at the first stages of growth and continue to grow.

In order to confirm the nanocrystalline layer consists of diamond, Raman measurements were performed (Fig. 2) to distinguish between carbon allotropes and to estimate the ratio of $\mathrm{sp}^{2}$ versus $\mathrm{sp}^{3}$ within the film. Since the bond energy for $\mathrm{sp}^{2}$ carbons is higher, their signal is shifted to higher wavenumber compared to the signal for diamond, located at $1332 \mathrm{~cm}^{-1}$. The $\mathrm{G}$ band (characteristic for graphite) typically lies around $1550 \mathrm{~cm}^{-1} \cdot{ }^{34}$ In nano- or polycrystalline 
diamond other signature peaks of $\mathrm{sp}^{2}$ carbon can arise, i.e. the $\mathrm{D}$ band, characteristic for defects in $\mathrm{sp}^{2}$ phases, lies around $1350 \mathrm{~cm}^{-1}$ and if trans-polyacetylene is present at the grain boundaries this causes a peak around $1450 \mathrm{~cm}^{-1} \cdot{ }^{35,36,37}$ The intense signal around $1332 \mathrm{~cm}^{-1}$ and the very low intensity of peaks situated around 1480 and $1550 \mathrm{~cm}^{-1}$, confirm that a high quality diamond layer with a very low amount of $\mathrm{sp}^{2}$ bonded carbon was deposited. The $\mathrm{sp}^{3}$ content is estimated to be $(0.98 \pm 0.05)$ based on a procedure described by Silva et al. ${ }^{38}$

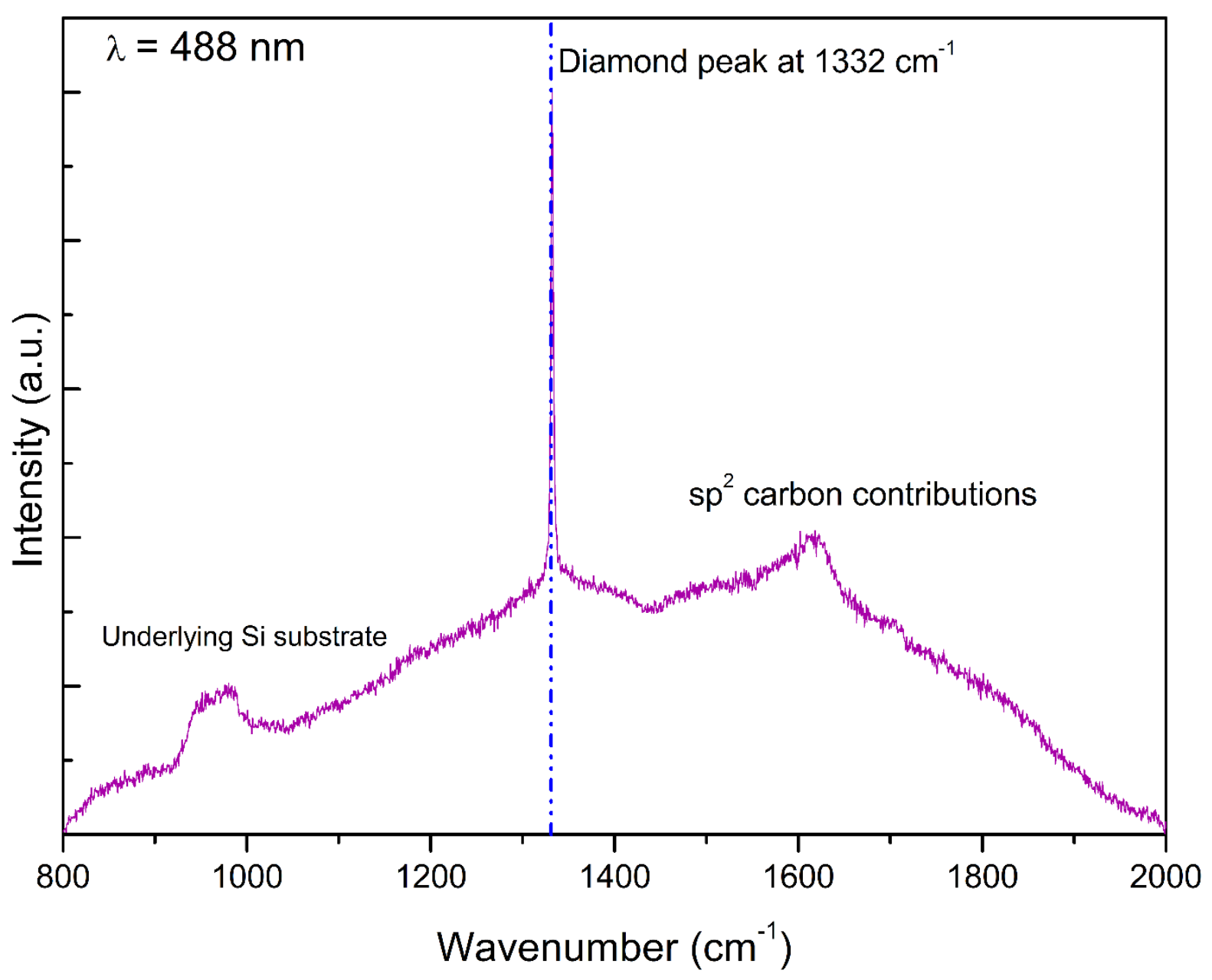

Figure 2. Raman spectrum of a $130 \mathrm{~nm}$ thick NCD sample grown at $410{ }^{\circ} \mathrm{C}, 0.17$ Torr, $2.8 \mathrm{~kW}$ CW power, $2.5 \% \mathrm{CH}_{4}$ and $6 \% \mathrm{CO}_{2}$ without external heating.

The NCD layer was further analysed with TEM to characterise its crystallography and morphology. Similar to SEM images, plan view annular dark field (ADF) and bright field (BF) 
scanning transmission electron microscopy (STEM) images show the co-existence of both octahedral and plate structure diamond grains (Fig. 3).

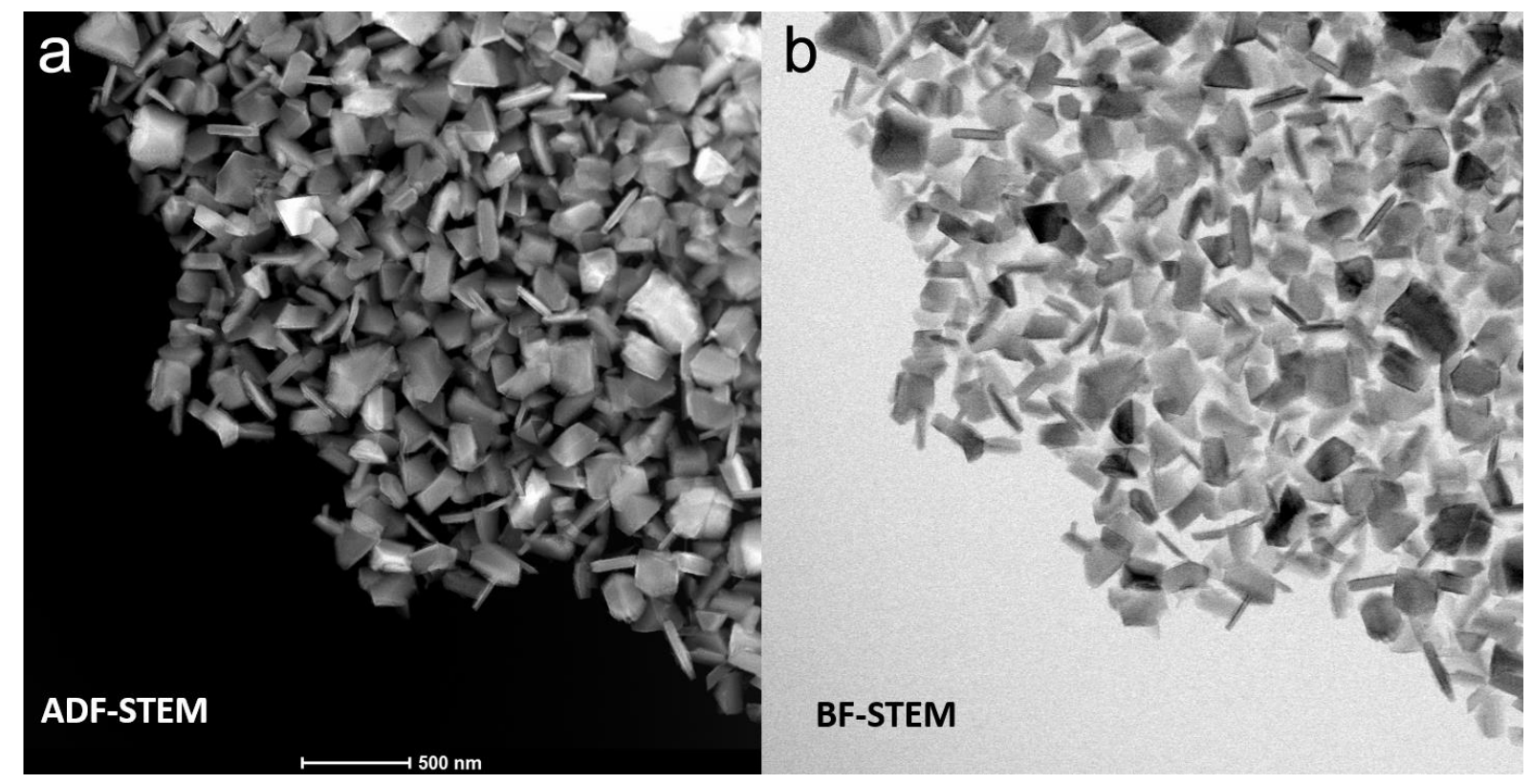

Figure 3. Plan view Annular Dark Field (a) and Bright Field (b) Scanning Transmission Electron Microscopy image of a $130 \mathrm{~nm}$ thick NCD layer, that was thinned for TEM imaging, deposited with a LA MW PE CVD system showing the presence of both octahedral and plate diamond grains.

Cross-sectional BF TEM studies reveal both plates and octahedral grains (Fig. 4a). The inset in figure $4 \mathrm{~b}$ shows the selected area electron diffraction (SAED) pattern of a diamond plate. This diffraction pattern corresponds to the diffraction pattern of cubic diamond when the grain is imaged in the [011] zone axis. This plate diamond grain (with $\{111\}$ terminating facets) is connected to the next grain via a $\{111\}$ plane. The octahedral grain in region c, shown in figure $4 \mathrm{c}$, mainly has $\{111\}$ terminating facets. This grain also contains a lot of stacking faults, which can be recognised by the lines in the fast Fourier transform (FFT) pattern from that area (Fig. $4 \mathrm{c}$ left inset). The least defective part of that grain shows a cubic diamond SAED pattern in the [011] zone axis (Fig. 4c right inset), and the larger fuzzy dots pattern in the HRTEM image, i.e. 
bend contours, are an indication of stress in the grain. (The TEM specimen is slightly bent at various positions, which means Bragg's law is not fulfilled at these spots and this leads to a difference in diffraction contrast.)
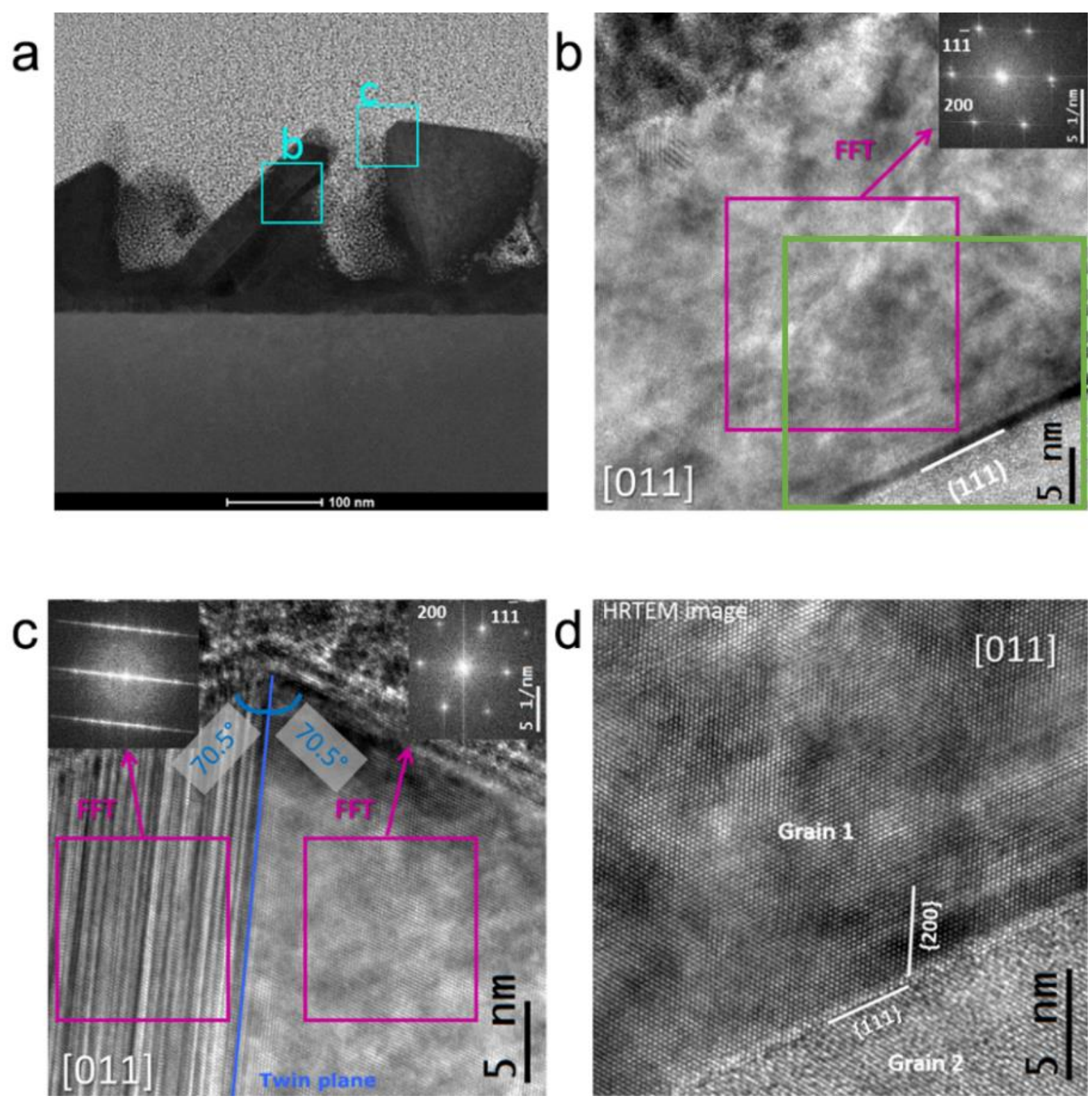

Figure 4. a) Bright field TEM image. The blue squares indicate the zones examined in (b) and (c), but rotated $20^{\circ}$ clockwise. b) High resolution TEM image of a plate grain. c) High resolution TEM image of an octahedral grain. d) Zoomed HRTEM image of the area indicated by the green rectangle in (b). 
The different areas are joint by a twin plane, indicated in blue, which demonstrates how two $\{111\}$ planes at the edge of a grain appear to have a $141^{\circ}$ angle, that is actually the sum of two $70.53^{\circ}$ angles between the twin plane and the edge plane. High resolution TEM (Fig. 4d) shows that the plates are terminated by large $\{111\}$ surface facets and that the plate grain lays straight in the [110] zone axis, while the neighbouring grain has a different orientation. Moreover, the grain boundaries are shown to be quite sharp, which is an indication of very little disorder in between the grains, which was also shown by the very low $\mathrm{sp}^{2}$ carbon content as determined by Raman spectroscopy.

The composition and atomic structure of the diamond plates was examined with electron energy loss spectroscopy (EELS) characterisation, as shown in figure 5. Elemental mapping of the NCD layers via EELS reveals that the grains consist of diamond, but that they are covered with a silicon dioxide layer. The amorphous carbon layer on top of the diamond layer is due to sample preparation. The near-edge structure of the carbon K-edge in EELS (Fig. 5c) confirms that the grains are indeed diamond, i.e. in an $\mathrm{sp}^{3}$ chemical bonding state. Moreover there is a very small shoulder at $285 \mathrm{eV}$ at the edge of the grain corresponding to the $\pi$ orbital of $\mathrm{sp}^{2}$ carbon, i.e. there is a very low amount of $\mathrm{sp}^{2}$, estimated to be $2.6 \pm 0.5 \%$, in the grain boundary. Thus, EELS confirms that the grains consist of high quality diamond and that the grain boundaries are very clean and sharp with a very low amount of $\mathrm{sp}^{2}$ bonded carbon. 

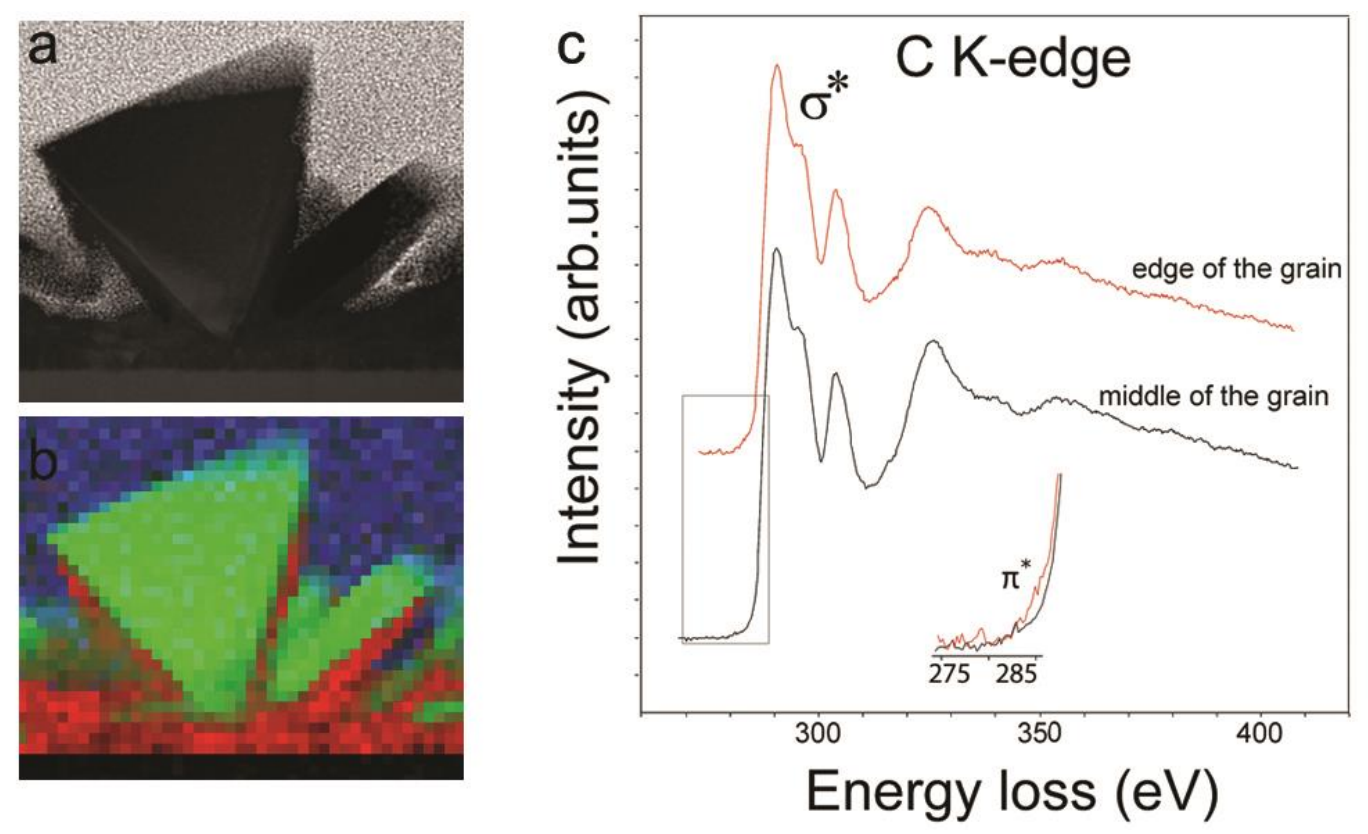

Figure 5. a) ADF-STEM and b) EELS map showing the layer consists of diamond grains. (Blue: amorphous carbon, Green: diamond, Red: oxygen related to silicon dioxide) c) Nearedge structure of carbon K-edge in EELS.

EDX mapping, in figure 6, confirms that the diamond particles are covered with a silicon dioxide layer. The source of the silicon can be twofold: the silicon substrate was etched and resputtered during TEM sample preparation, or the quartz tubes surrounding the antennas were etched during growth. As the gas mixture contains oxygen, silicon present during the growth phase could be deposited in the form of silicon dioxide. In order to clarify the origin of $\mathrm{Si}$, an NCD layer was prepared on a molybdenum substrate. EDX mapping also shows the presence of a Si layer on a Mo substrate (Fig. 6e), which means Si is most probably being etched from the quartz tubes in oxygen-rich growth conditions, i.e. in presence of $\mathrm{CO}_{2},{ }^{39}$ and is co-deposited with the NCD layer. So far, we don't have any proof of silicon oxide embedded in the grains. EELS mapping (Fig. 5) shows a very high quality of the diamond grains without the presence of Si. The red pixels on the EDX map in the middle of the grain are most probably due to the background of the spectrum which is impossible to avoid completely. Moreover, the EDX map was taken plan view and the signal might come from the surface. EDX and EELS give clear 
evidence that $\mathrm{Si}$ is present at the grain boundaries and not within the grains, otherwise, big impurities of $\mathrm{Si}$ oxide would have been found. Since the grains are only covered with $\mathrm{SiO}_{2}$ and there is no proof of significant incorporation of impurities into the grains, it is argued that the properties of the diamond film are not influenced directly by impurity atoms. Furthermore, such a thin Si dioxide surface layer can easily be removed by a short HF etching step, to obtain a pure diamond film. Indirectly, it is thought that the properties are changed because the crystalline structure, i.e. the stacking order, is influenced by the presence of Si.

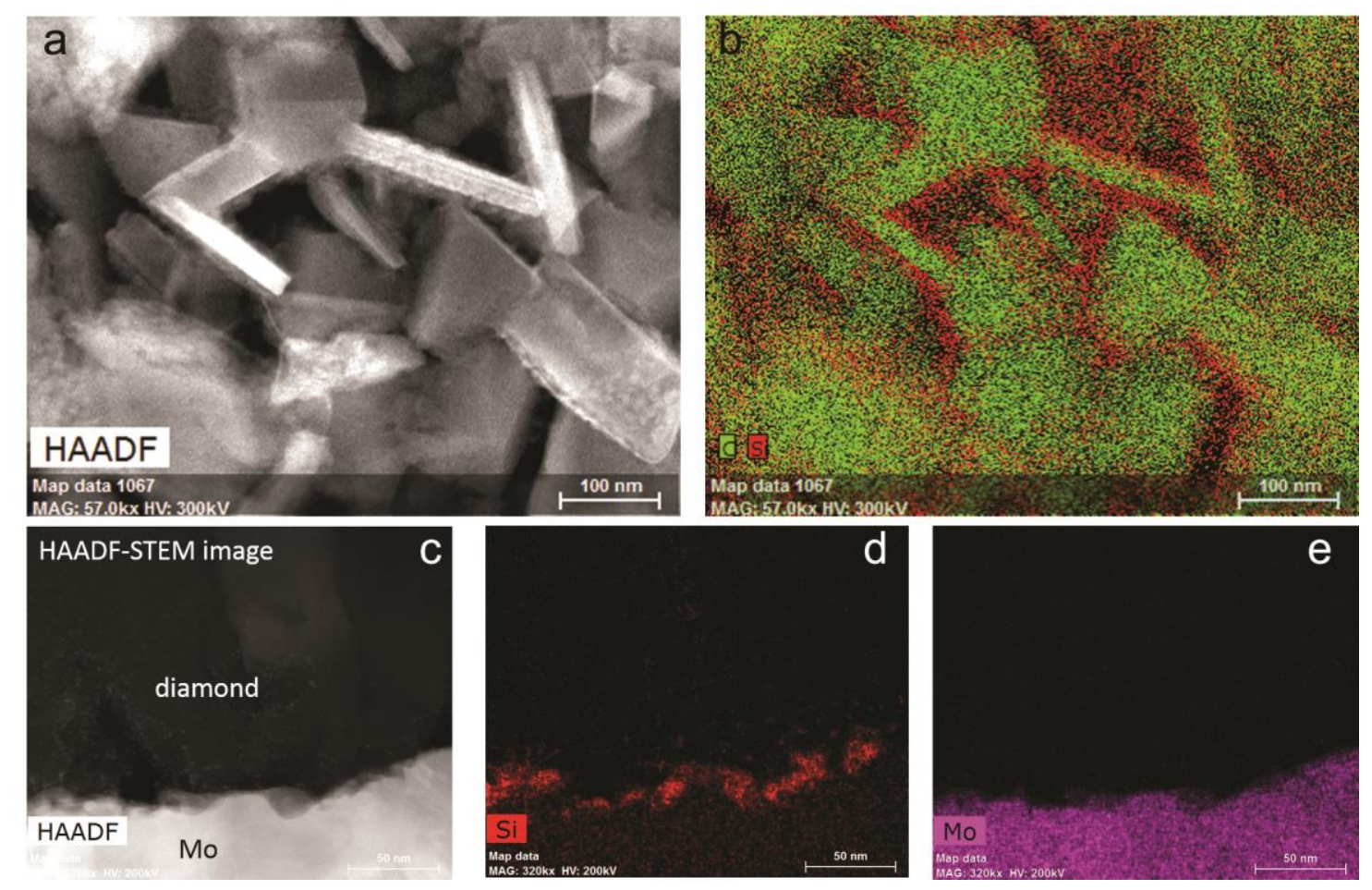

Figure 6. a) High-angle annular dark-field image of a $130 \mathrm{~nm}$ thick nanocrystalline diamond layer deposited on Si b) EDX map of (a) (Green: carbon and red: silicon), showing the coverage of the diamond grains with silicon. c) High-angle annular dark-field scanning transmission electron microscopy image of a $130 \mathrm{~nm}$ thick nanocrystalline diamond layer deposited on Mo, d) and e) Cross-sectional EDX mapping of (c) showing the presence of a Si layer on a Mo substrate. 


\section{Proposed mechanisms}

\section{Impurity induced formation of stacking faults}

As discussed, stacking faults present at the start of the deposition process are the driving force behind this anisotropic morphology to develop, since they create self-perpetuating growth steps. Nevertheless, it is still unclear why these stacking faults develop. In previous experiments performed with an ASTeX PDS-17 system, diamond plates were grown under conditions with a high amount of excited species, at temperatures above $1150{ }^{\circ} \mathrm{C}$ with a $\mathrm{CH}_{4}$ concentration of

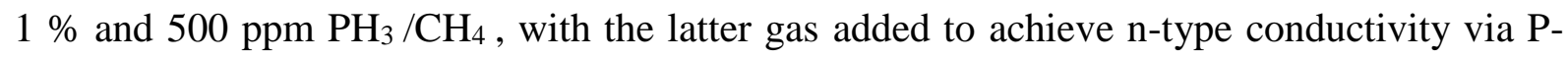
doping. The substrate was a diamond single crystal (110) HPHT substrate polished with a $10^{\circ}$ off-angle towards [100]. The plates in this sample form an angle of $70^{\circ}$ with respect to each other, as shown in figure 7 ; thereby confirming that these plates also have $\{111\}$ terminating facets. And although the growth of $\{111\}$ facets on (110) crystals has been reported before, the obtained plate morphology is distinctly different from (111)-oriented microfacets that lead to a rough appearance. ${ }^{40,41}$ These microfacets are induced by pre-growth polishing of (110), because diamond preferentially chips along the (111) cleavage planes. ${ }^{41}$

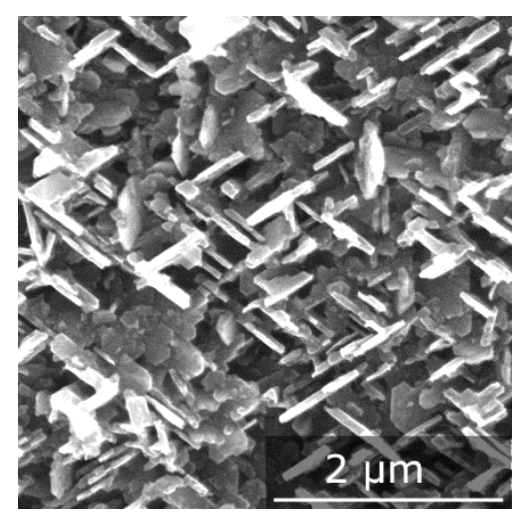

Figure 7. SEM image of a layer deposited with an ASTeX resonant cavity MW PE CVD system

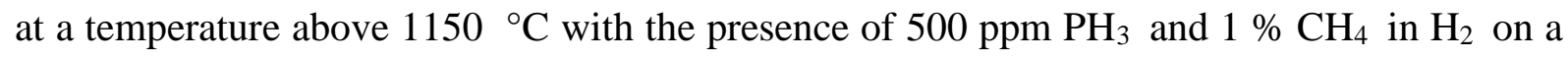
(110) HPHT diamond single crystal substrate polished with a $10^{\circ}$ off-angle towards [100]. 
A first suggestion for the development of stacking faults in the presented low temperature experiments is based on the analysis of the obtained crystal structure. Based on the fact that a stacking fault consists of one or more layers of hexagonal diamond, for which the formation mechanism is known, a mechanism for the development of these diamond plates is proposed. It is important to note that the actual existence of hexagonal diamond is being questioned and it has never been reported to exist as a separate, pure material. ${ }^{42}$ Németh et al. offered experimental evidence to show that what has been considered as hexagonal diamond up to now is actually faulty and twinned cubic diamond, i.e. comparable to the plates obtained in this work but with a higher degree of faults. This means the mechanism of hexagonal diamond, proposed by Kang and co-workers, could be considered as a mechanism for the development of faulty cubic diamond, ${ }^{43}$ possibly also explaining the development of diamond plates in our experiments. In the experiments of Kang and co-workers the deposition is performed on a layer of $\mathrm{Al} / \mathrm{Ni} / \mathrm{Al}$, which is annealed prior to growth to form nanoparticles. These nanoparticles act as a catalyst for the formation of stacking faults. During the first growth steps, an amorphous carbon film covers the nanoparticles. More specifically a fullerene encapsulates the nanoparticle, since $\mathrm{Al}$ nanoparticles are known to improve the formation of fullerenes. ${ }^{44}$ This fullerene keeps developing, i.e. adding layers like onion shells, but since at this size nanodiamond structures are more stable than fullerene, an $\mathrm{sp}^{3}$ nucleus starts to develop. ${ }^{45,46}$ The orientation of the plate depends on the location on the fullerene shell where the atom nucleates. If the atom bonds on top, the plate will be (almost) parallel to the substrate, in case it nucleates close to the base of the fullerene, i.e. close to the surface, the plate will be perpendicular to the surface. With this model it is still unclear why the nucleation on a fullerene results in a hexagonal diamond layer instead of a cubic diamond one. Therefore, a closer look into the crystallographic structure is necessary. Simulations of high pressure transformations from 
hexagonal $\mathrm{sp}^{2}$ into $\mathrm{sp}^{3}$ carbon have shown that in order to form cubic diamond a buckling and slipping mechanism of adjacent graphitic layers needs to take place, while for hexagonal diamond no buckling takes place. ${ }^{47}$ Therefore, at certain interlayer distances it is energetically more favourable to form hexagonal instead of cubic diamond. Experimental results supporting these simulations have been reported by Zhang et al. ${ }^{48}$

Based on previous reports (discussed above and by others) and our current results, it is argued that a similar transition from fullerene to diamond can occur in CVD processes as well. ${ }^{49,50}$ The assumption that impurity atoms are important for this mechanism to occur is based on the literature reports of diamond plates up to now. Most of the papers discussed above report the presence of a foreign material during the deposition conditions (see table 1).

Table 1. Summary of the important factors for the development of diamond plates.

\begin{tabular}{|c|c|c|c|c|}
\hline & $\begin{array}{l}\text { Temperatu } \\
\text { re }\end{array}$ & {$\left[\mathrm{CH}_{4}\right]$} & Impurity & Deposition system \\
\hline Angus $1992^{9}$ & $850^{\circ} \mathrm{C}$ & $1 \%$ & / & $\begin{array}{l}\text { ASTeX resonant cavity } \\
\text { PDS } 16 \text { MW PE CVD }\end{array}$ \\
\hline Lu2004 ${ }^{10}$ & $>1000{ }^{\circ} \mathrm{C}$ & $0.667 \%$ & $\mathrm{Fe}$ & $\begin{array}{l}2.45 \mathrm{GHz} \text { ASTeX } \\
\text { resonant cavity } \mathrm{MW} \mathrm{PE} \\
\text { CVD }\end{array}$ \\
\hline Chen2004, Chen2005 ${ }^{11,18}$ & $>1000{ }^{\circ} \mathrm{C}$ & $3 \%$ & $\mathrm{Ni}$ & $\begin{array}{l}2.45 \mathrm{GHz} \text { ASTeX } \\
\text { resonant cavity } \mathrm{MW} \mathrm{PE} \\
\text { CVD }\end{array}$ \\
\hline
\end{tabular}




\begin{tabular}{|c|c|c|c|c|}
\hline $\mathrm{Lu} 2005^{19}$ & $>1150{ }^{\circ} \mathrm{C}$ & $0.667 \%$ & I & $\begin{array}{l}2.45 \mathrm{GHz} \text { ASTeX } \\
\text { resonant cavity } \mathrm{MW} \mathrm{PE} \\
\text { CVD }\end{array}$ \\
\hline Chen $2008^{20}$ & $>1000^{\circ} \mathrm{C}$ & $1-3 \%$ & $\begin{array}{l}\mathrm{Au} / \mathrm{Ge} \quad \text { or } \\
\mathrm{NCD} \text { films }\end{array}$ & $\begin{array}{l}2.45 \mathrm{GHz} \text { ASTeX } \\
\text { resonant cavity MW PE } \\
\text { CVD }\end{array}$ \\
\hline Alekseev2016 ${ }^{12}$ & $\begin{array}{l}1000- \\
1100^{\circ} \mathrm{C}\end{array}$ & $3 \%$ & / & $\begin{array}{l}\text { Direct current discharge } \\
\text { PE CVD }\end{array}$ \\
\hline
\end{tabular}

A foreign atom cluster catalyses the formation of a fullerene which later easily transforms into hexagonal diamond because of the lattice similarities of the stacked graphene layers with hexagonal diamond. ${ }^{44,51}$ However, both cubic and hexagonal diamond nuclei can form because at these sizes diamond is more stable than fullerene. ${ }^{45,46}$ In this way, cubic diamond with hexagonal stacking faults can develop.

From EDX and EELS, it is clear that $\mathrm{Si}$ is present between the diamond grains. In addition, the presence of trace amounts of aluminium in the gas phase cannot be ruled out, since the chamber walls consist of aluminium and there is a typical content of about $15 \mathrm{ppm}$ of aluminium inside the quartz tubes. ${ }^{52}$ Optical emission spectroscopy is a powerful tool to reveal the plasma characteristics that might be responsible for the growth mechanisms behind this particular morphology. However, the signals of the elements of interest, $\mathrm{Al}$ and $\mathrm{Si}$, are either out of the range of our current set-up or are in a range in which it is difficult to distinguish between other species. Si shows a very strong signal at $288 \mathrm{~nm}$, but the lower range of our set-up is about 320 nm. ${ }^{53}$ There are some peaks between 409 and 422 (Fig. 8), that could be assigned to $\mathrm{SiH}^{*}$ and in combination with the already discussed presence of Si in the layers, based on EDX and EELS, 
it is very likely that these OES peaks are indeed Si-related. ${ }^{54,55}$ For aluminium, the characteristic peak is located at $632 \mathrm{~nm}$, but the peak at this location in the spectrum in figure $8 \mathrm{a}$ is due to the laser used for in-situ thickness measurements $(\lambda=632 \mathrm{~nm}) .{ }^{53}$ Spectra recorded without the presence of the laser (Fig. 8c) only show a very small signal at the wavelength of interest but since the molecular hydrogen band covers the entire range from $570-640 \mathrm{~nm}$, no further conclusions can be drawn with respect to possible Al presence in the plasma. ${ }^{24,56}$
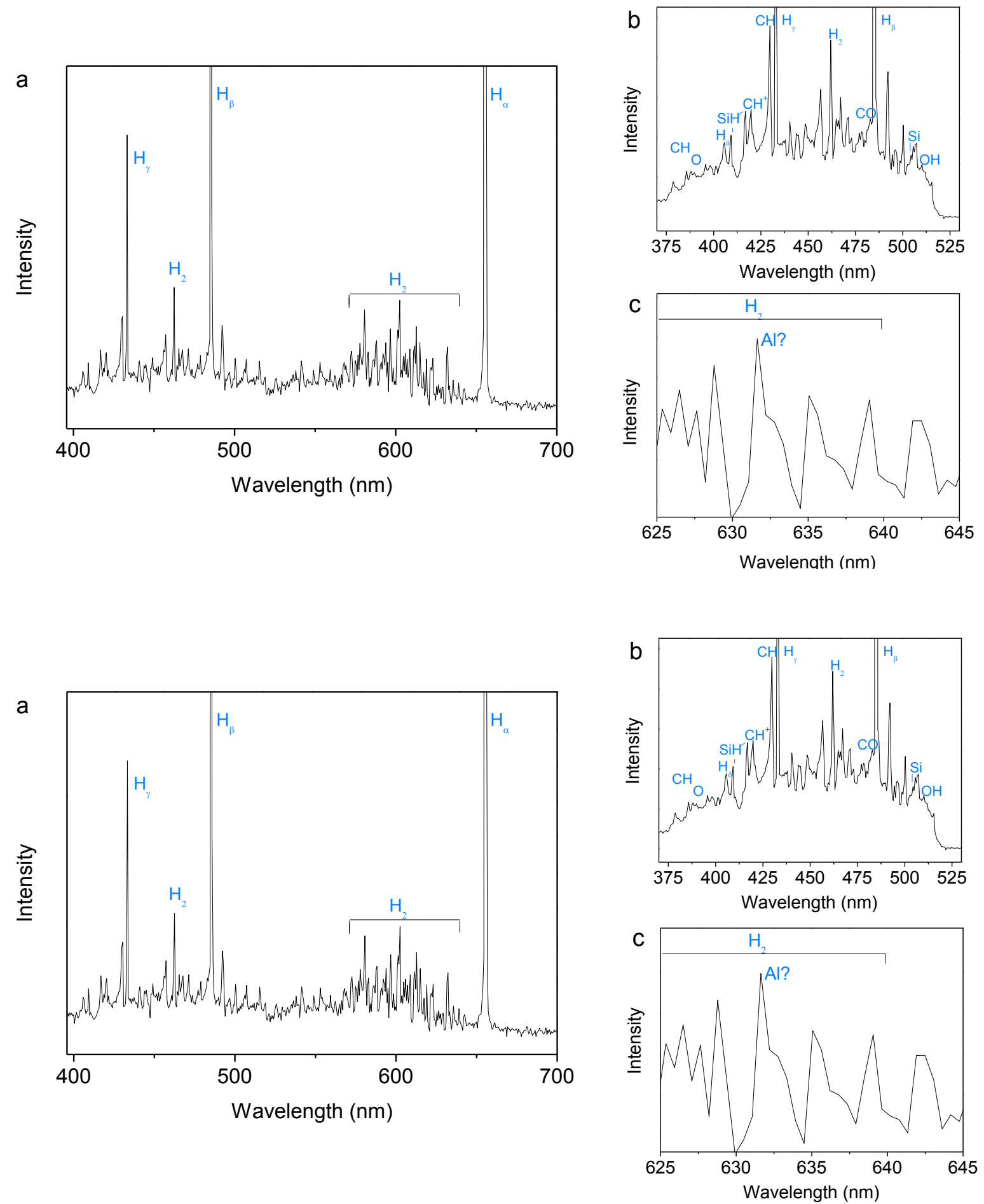
Figure 8. a) Optical emission spectrum of the plasma with deposition conditions $410{ }^{\circ} \mathrm{C}, 0.17$ Torr, $2.8 \mathrm{~kW} \mathrm{CW}$ power, $2.5 \% \mathrm{CH}_{4}$ and $6 \% \mathrm{CO}_{2}$ without external heating with the in-situ thickness measurements laser switched on b) Zoom of the range between 370 and $530 \mathrm{~nm}$ and c) Zoom of the range between 625 and $645 \mathrm{~nm}$ with the laser switched off.

\section{Impurity induced blocking layer for the growth of a crystal facet}

A first alternative is the formation of a growth blocking layer on one type of crystal facet. This blocking layer can be formed preferentially at one crystal facet because of a better match between the spacing of the available carbon atoms and/or a higher surface energy of a that particular facet. The density of surface atoms depends on the crystal facet; i.e. there are 1.83 . $10^{15}$ surface atoms $\mathrm{cm}^{-2}$ at $\{111\}, 2.23 \cdot 10^{15} \mathrm{~cm}^{-2}$ at $\{110\}$ and $1.5610^{15} \cdot \mathrm{cm}^{-2}$ at $\{100\}{ }^{57}$ These surface atoms can bond with a foreign atom like silicon, which is also a group IV element with a radius of $117.6 \mathrm{pm}$. The formation of a silicon terminated (100) diamond surface, for instance, has been achieved by the deposition of a silicon adlayer and subsequent annealing and has proven to be very stable up to high temperatures. ${ }^{58}$ The surface energy of the crystal facets depends on the deposition temperature. At lower temperatures, $\{100\}$ is the most stable and $\{111\}$ is the most reactive, while at higher temperatures the reactivities are inversed and $\{111\}$ becomes the most stable crystal facet. ${ }^{57}$ The exact location of this inversion point depends on the pressure and specific growth conditions. In the case that the $\{111\}$ crystal facets have the highest surface energy they are the most likely planes to bond with Si thereby forming a capping layer which impedes further growth of this plane, leading to diamond plates. Similar mechanisms are known to take place during the growth of crystals with the use of CVD techniques and during solution based growth in presence of a surfactant. ${ }^{59}$ 


\section{Impurity enhanced etching of a crystal facet}

The second alternative for the development of diamond plates is based on enhanced etching of a particular crystal facet. The direct oxidation and corrosion of $\{111\}$ planes has been reported to occur more easily than that of $\{110\}$ planes. ${ }^{60}$ In addition, impurities can be responsible for the formation of surface compounds that are easily removed from the growing diamond crystal and thereby removing carbon atoms. Similar to the assumption made above, if $\{111\}$ crystal facets have the highest surface energy they are the most likely planes to bond with $\mathrm{Si}$. If the formed surface compounds are etched easily, this will lead to the formation of plates. A possible route for the removal of surface carbon atoms is similar to the beta-scission reaction, i.e. a methyl radical first binds to the diamond lattice followed by the addition of a $\mathrm{SiH}_{3}$ radical.. Once $\mathrm{SiH}_{3}$ is covalently bonded to a singly bonded carbon atom at a lattice site, an atomic hydrogen could abstract a hydrogen to form a radical at $\mathrm{Si}$ and via a beta-scission reaction a methylenesilane could be released into the plasma, leaving a radical at the surface. This mechanism would lead to enhanced etching of $\{111\}$ facets, which could account for the formation of diamond plates.

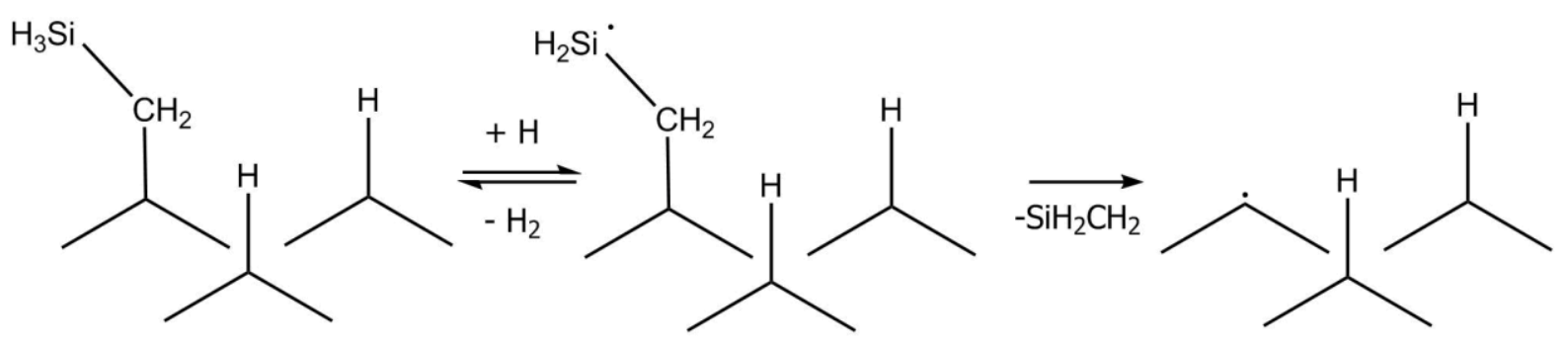

Figure 9. Adapted beta-scission reaction upon addition of a $\mathrm{SiH}_{3}$ radical. Based on the model proposed by Butler and Oleynik. $^{23}$

The presence of silicon on the surface of the grains hints at mechanism two and/ three. But from the EDX maps on the Mo sample it is clear that a Si layer formed at the interface between the diamond layer and the Mo substrate, which means mechanism one cannot be excluded . 
In order to gain more insight into the mechanism responsible for plate formation, a more detailed plasma characterisation and plasma modelling should be performed. ${ }^{61-63}$ While the electron temperature and density can be determined via Langmuir probe measurements, the gas species present can be probed via infrared laser absorption spectroscopy. Furthermore, computational calculations using density functional theory could give more insight into the mechanism responsible for plate formation. The binding energies of $\mathrm{Si}$ and $\mathrm{SiH}_{3}$ to $\{111\}$ and $\{100\}$ diamond facets and the reaction energy of the beta-scission reaction are necessary to predict the dominant mechanism. Additional experiments, in which the diamond seeding is replaced with Si nanoparticles, could also be interesting in order to verify the first mechanism proposed.

\section{Conclusion}

We report the co-deposition of high aspect ratio diamond plates and octahedral diamond grains with linear antenna MW PE CVD technology forming nanocrystalline diamond films at low deposition temperatures $\left(320-410{ }^{\circ} \mathrm{C}\right)$. Up to now, the diamond plate structure was only observed after high temperature deposition experiments, and the initiation of the diamond plate growth mechanism remained unclear. Based on the current results, three potential growth models are proposed for the development of diamond plates with linear antenna MW PE CVD technology. The formation of plates could be attributed to the presence of clusters of impurity atoms that are eventually encapsulated by catalyzing the formation of fullerenes that are subsequently transformed into hexagonal diamond. Once a defective hexagonal diamond nucleus is formed, it will continue to exist because of its regenerative nature. The growth of the eventual plate is a result of the interplay between fast and slow growing sites. An alternative proposition puts the preferential bonding of impurity atoms to $\{111\}$ diamond planes forward because of better lattice matching and a higher surface energy of this facet. This will either lead 
to enhanced etching of those $\{111\}$ facets, or to the formation of an impurity-containing growth blocking layer and both processes will lead to the formation of diamond plates.

\section{AUTHOR INFORMATION}

\section{Corresponding Author}

*sien.drijkoningen@uhasselt.be, ${ }^{+}$ken.haenen@uhasselt.be.

\section{Author Contributions}

The manuscript was realized through contributions of all authors. SD designed experiments, carried out the diamond film depositions in the linear antenna system, performed SEM characterization and wrote the manuscript. Raman measurements were performed by AM and PP. SK performed TEM, EELS and EDX characterization. YB performed diamond film deposition in ASTeX resonant cavity MW PE CVD system.

KH and MN coordinated the study and checked the manuscript.

All authors, including ST, JV and MKVB, discussed the obtained results and have given approval to the final version of the manuscript.

\section{ACKNOWLEDGEMENTS}

The Research Foundation - Flanders (FWO) is gratefully acknowledged for financial support in the form of the Postdoctoral Fellowships of PP and ST, contract G.0044.13N 'Charge ordering' (SK, JV), the Methusalem "Nano" network, and the Hercules-linear antenna and Raman equipment.

\section{REFERENCES}

(1) Sankaran, K. J.; Hoang, D. Q.; Srinivasu, K.; Korneychuk, S.; Turner, S.; Drijkoningen, 
S.; Pobedinskas, P.; Verbeeck, J.; Leou, K. C.; Lin, I. N.; Haenen, K. Phys. status solidi 2016, 213, 2654-2661.

(2) Koeck, F. A. M.; Nemanich, R. J.; Lazea, A.; Haenen, K. Diam. Relat. Mater. 2009, 18, $789-791$.

(3) Nelz, R.; Fuchs, P.; Opaluch, O.; Sonusen, S.; Savenko, N.; Podgursky, V.; Neu, E. Appl. Phys. Lett. 2016, 109, 193105.

(4) Yang, Y.; Yuen, M.-F.; Chen, X.; Xu, S.; Tang, Y.; Zhang, W.; Tsai, J.; Chen, L. C.; Chen, K. H.; Russell, J. N.; Smith, L. M.; Hamers, R. J.; Park, H. CrystEngComm 2015, 17, 2791-2800.

(5) Wild, C.; Kohl, R.; Herres, N.; Müller-Sebert, W.; Koidl, P. Diam. Relat. Mater. 1994, 3, 373-381.

(6) Silva, F.; Achard, J.; Bonnin, X.; Brinza, O.; Michau, A.; Secroun, A.; De Corte, K.; Felton, S.; Newton, M.; Gicquel, A. Diam. Relat. Mater. 2008, 17, 1067-1075.

(7) Masuda, H.; Yanagishita, T.; Yasui, K.; Nishio, K.; Yagi, I.; Rao, T. N.; Fujishima, A. Adv. Mater. 2001, 13, 247-249.

(8) Shang, N.; Papakonstantinou, P.; Wang, P.; Zakharov, A.; Palnitkar, U.; Lin, I.-N.; Chu, M.; Stamboulis, A. ACS Nano 2009, 3, 1032-1038.

(9) Angus, J. C.; Sunkara, M.; Sahaida, S. R.; Glass, J. T. J. Mater. Res. 1992, 7, 3001-3009.

(10) Lu, C.-A.; Chang, L. Diam. Relat. Mater. 2004, 13, 2056-2062.

(11) Chen, H.-G.; Chang, L. J. Mater. Res. 2005, 20, 703-711.

(12) Alexeev, A. M.; Ismagilov, R. R.; Ashkinazi, E. E.; Orekhov, A. S.; Malykhin, S. A.; Obraztsov, A. N. Diam. Relat. Mater. 2016, 65, 13-16.

(13) Kiflawi, I.; Lang, A. R. Nature 1977, 267, 36-37.

(14) Hamilton, D. R.; Seidensticker, R. G. J. Appl. Phys. 1960, 31, 1165.

(15) Ming, N.; Sunagawa, I. J. Cryst. Growth 1988, 87, 13-17. 
(16) Kirkland, A. I.; Jefferson, D. A.; Duff, D. G.; Edwards, P. P.; Gameson, I.; Johnson, B. F. G.; Smith, D. J. Proc. R. Soc. A Math. Phys. Eng. Sci. 1993, 440, 589-609.

(17) Bögels, G.; Pot, T. M.; Meekes, H.; Bennema, P.; Bollen, D. Acta Crystallogr. Sect. A Found. Crystallogr. 1997, 53, 84-94.

(18) Chen, H.-G.; Chang, L. Diam. Relat. Mater. 2004, 13, 590-594.

(19) Lu, C.-A.; Chang, L. Mater. Chem. Phys. 2005, 92, 48-53.

(20) Chen, H.-G.; Chang, L.; Cho, S.-Y.; Yan, J.-K.; Lu, C.-A. Chem. Vap. Depos. 2008, 14, $247-255$.

(21) Sunkara, M. K. Monte-Carlo Simulation of Diamond Nucleation and Growth, Case Western Reserve University, 1993.

(22) Ringe, E.; Van Duyne, R. P.; Marks, L. D. J. Phys. Chem. C 2013, 117, 15859-15870.

(23) Butler, J. E.; Oleynik, I. Philos. Trans. A. Math. Phys. Eng. Sci. 2008, 366, 295-311; discussion 311.

(24) Tsugawa, K.; Kawaki, S.; Ishihara, M.; Kim, J.; Koga, Y.; Sakakita, H.; Koguchi, H.; Hasegawa, M. Diam. Relat. Mater. 2011, 20, 833-838.

(25) Taylor, A.; Fendrych, F.; Fekete, L.; Vlček, J.; Řezáčová, V.; Petrák, V.; Krucký, J.; Nesládek, M.; Liehr, M. Diam. Relat. Mater. 2011, 20, 613-615.

(26) Potocký, Š.; Babchenko, O.; Davydova, M.; Izak, T.; Čada, M.; Kromka, A. Jpn. J. Appl. Phys. 2014, 53, 05FP04.

(27) Sangwal, K. Prog. Cryst. Growth Charact. Mater. 1996, 32, 3-43.

(28) Palyanov, Y. N.; Khokhryakov, A. F.; Borzdov, Y. M.; Kupriyanov, I. N. Cryst. Growth Des. 2013, 13, 5411-5419.

(29) Kern, W. A.; Puotinen, D. A. RCA Rev. 1970, 31, 187-206.

(30) Williams, O. A.; Douhéret, O.; Daenen, M.; Haenen, K.; Ósawa, E.; Takahashi, M. Chem. Phys. Lett. 2007, 445, 255-258. 
(31) Sun, B.; Zhang, X.; Zhang, Q.; Lin, Z. J. Appl. Phys. 1993, 73, 4614.

(32) Stiegler, J.; Lang, T.; Nyga ${ }^{\circ}$ rd-Ferguson, M.; von Kaenel, Y.; Blank, E. Diam. Relat. Mater. 1996, 5, 226-230.

(33) Vlček, J.; Fendrych, F.; Taylor, A.; Kratochvílová, I.; Fekete, L.; Nesládek, M.; Liehr, M. Mater. Res. Soc. Symp. Proc. 2010, 1203.

(34) Ballutaud, D.; Jomard, F.; Kociniewski, T.; Rzepka, E.; Girard, H.; Saada, S. Diam. Relat. Mater. 2008, 17, 451-456.

(35) Knight, D. S.; White, W. B. J. Mater. Res. 1989, 4, 385-393.

(36) Ferrari, a.; Robertson, J. Phys. Rev. B 2001, 63, 121405.

(37) Mortet, V.; Zhang, L.; Eckert, M.; D’Haen, J.; Soltani, A.; Moreau, M.; Troadec, D.; Neyts, E.; De Jaeger, J.-C.; Verbeeck, J.; Bogaerts, A.; Van Tendeloo, G.; Haenen, K.; Wagner, P. Phys. status solidi 2012, 209, 1675-1682.

(38) Silva, F.; Gicquel, A.; Tardieu, A.; Cledat, P.; Chauveau, T. Diam. Relat. Mater. 1996, $5,338-344$.

(39) Izak, T.; Sveshnikov, A.; Demo, P.; Kromka, A. Phys. Status Solidi 2013, 250, $2753-$ 2758.

(40) Haenen, K.; Lazea, A.; Barjon, J.; D’Haen, J.; Habka, N.; Teraji, T.; Koizumi, S.; Mortet, V. J. Phys. Condens. Matter 2009, 21, 364204-364210.

(41) Nishitani-Gamo, M.; Loh, K. P.; Sakaguchi, I.; Takami, T.; Kusunoki, I.; Ando, T. J. Vac. Sci. Technol. A Vacuum, Surfaces, Film. 1999, 17, 2991.

(42) Németh, P.; Garvie, L. A. J.; Aoki, T.; Dubrovinskaia, N.; Dubrovinsky, L.; Buseck, P. R. Nat. Commun. 2014, 5, 5447.

(43) Kang, K.; Jin, Y.; Kim, J.; Ajmera, P. K. Diam. Relat. Mater. 2012, 27, 76-81.

(44) Xu, B. .; Tanaka, S.-I. Acta Mater. 1998, 46, 5249-5257.

(45) Badziag, P.; Verwoerd, W.; S.; Ellis, W.; P.; Greiner, N.; R. Nature 1990, 343, 244-245. 
(46) Shenderova, O. A.; Zhirnov, V. V.; Brenner, D. W. Crit. Rev. Solid State Mater. Sci. 2002, 27, 227-356.

(47) Xie, H.; Yin, F.; Yu, T.; Wang, J.-T.; Liang, C. Sci. Rep. 2014, 4, 51-55.

(48) Zhang, F.; Ahmed, F.; Holzhüter, G.; Burkel, E. J. Cryst. Growth 2012, 340, 1-5.

(49) Bhargava, S.; Bist, H. D.; Sahli, S.; Aslam, M.; Tripathi, H. B. Appl. Phys. Lett. 1995, 67, 1706.

(50) Nishitani-Gamo, M.; Sakaguchi, I.; Loh, K. P.; Kanda, H.; Ando, T. Appl. Phys. Lett. 1998, 73, 765 .

(51) Khaliullin, R. Z.; Eshet, H.; Kühne, T. D.; Behler, J.; Parrinello, M. Nat. Mater. 2011, $10,693-697$.

(52) Datasheet Quartz Tubes LA MW PE CVD system - QSIL-ilmasil-PN_e. http://www.qsil.com/files/online/Material/QSILilmasilPN_e.pdf (accessed May 30, 2016).

(53) Sansonetti, J. E.; Martin, W. C. Handbook of Basic Atomic Spectroscopic Data. http://www.nist.gov/pml/data/handbook/index.cfm (accessed Jun 1, 2016).

(54) Suchaneck, G.; Mönch, J.-P.; Schade, K.; Paul, W. J. Non. Cryst. Solids 1987, 90, $323-$ 326.

(55) Strahm, B.; Howling, A. A.; Hollenstein, C. Plasma Phys. Control. Fusion 2007, 49, B411-B418.

(56) Barshilia, H. C.; Mehta, B. R.; Vankar, V. D. J. Mater. Res. 1996, 11, 2852-2860.

(57) Zhang, Y.; Zhang, F.; Chen, G. Mater. Lett. 1994, 20, 39-42.

(58) Schenk, A.; Tadich, A.; Sear, M.; O’Donnell, K. M.; Ley, L.; Stacey, A.; Pakes, C. Appl. Phys. Lett. 2015, 106, 191603.

(59) Bakshi, M. S. Cryst. Growth Des. 2016, 16, 1104-1133.

(60) Sun, C. Q.; Xie, H.; Zhang, W.; Ye, H.; Hing, P. J. Phys. D. Appl. Phys. 2000, 33, 2196- 
2199.

(61) Richley, J. C.; Fox, O. J. L.; Ashfold, M. N. R.; Mankelevich, Y. A. J. Appl. Phys. 2011, 109, 63307.

(62) Ashfold, M. N. R.; May, P. W.; Petherbridge, J. R.; Rosser, K. N.; Smith, J. A.; Mankelevich, A.; Suetin, N. V. 2001.

(63) Richley, J. C.; Kelly, M. W.; Ashfold, M. N. R.; Mankelevich, Y. A. J. Phys. Chem. A 2012, 116, 9447-9458.

For Table of Contents Use Only

\section{On the origin of diamond plates deposited at low temperature}

Sien Drijkoningen ${ }^{1,2, *}$, Paulius Pobedinskas ${ }^{1,2}$, Svetlana Korneychuk ${ }^{3}$, Aleksandr Momot ${ }^{1,2}$, Yasodhaadevi Balasubramaniam ${ }^{1,2}$, Marlies K. Van Bael ${ }^{1,2}$, Stuart Turner ${ }^{3}$, Jo Verbeeck, Miloš Nesládek ${ }^{1,2}$, and Ken Haenen ${ }^{1,2,+}$

${ }^{1}$ Institute for Materials Research (IMO), Hasselt University, Wetenschapspark 1, B-3590 Diepenbeek, Belgium

2 IMOMEC, IMEC vzw, Wetenschapspark 1, B-3590 Diepenbeek, Belgium

${ }^{3}$ Electron Microscopy for Materials Science (EMAT), University of Antwerp, Antwerp, Belgium

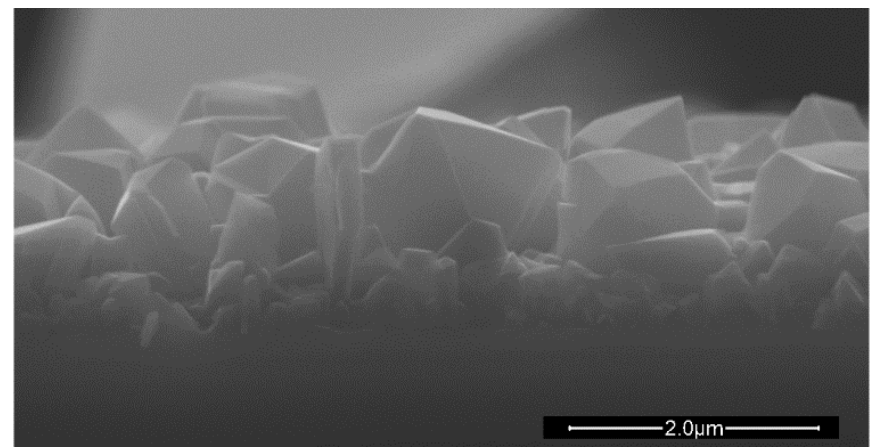

The co-deposition of plates and octahedral diamond grains at low temperatures $\left(\leq 410{ }^{\circ} \mathrm{C}\right)$ is reported. These plates are high quality, but faulty cubic diamond terminated by large $\{111\}$ 
surface facets with very little $\mathrm{sp}^{2}$ bonded carbon in the grain boundaries. Impurities are found to be responsible for the initial development of the observed plates rich with stacking faults. 